\title{
O uso de macroinvertebrados aquáticos como ferramenta de educação ambiental em uma escola municipal de Santarém, Pará
}

\author{
The use of aquatic macroinvertebrates as tool of environmental education in a \\ municipal school of Santarém, Pará
El uso de macroinvertebrados acuáticos como herramienta de educación ambiental en una escuela municipal de Santarém, Pará

Diego Ramos Pimentel ${ }^{1}$

Carla da Silva Paula ${ }^{2}$

Sheyla Regina Marques Couceiro ${ }^{3}$

\begin{abstract}
Resumo
$\mathrm{Na}$ avaliação de ambientes aquáticos, macroinvertebrados se destacam pela sensibilidade que apresentam aos diversos impactos antrópicos, assim esses organismos funcionam como bioindicadores da qualidade de ecossistemas. Neste sentido um estudo foi feito em um riacho urbano no município de Santarém-PA, onde se realizou coletas dos macroinvertebrados em três pontos desse riacho, em que os resultados mostraram alterações ambientais no ponto mais urbanizado. Esses resultados foram socializados para alunos em uma escola da Rede Municipal de Ensino de Santarém com aula expositiva, apresentação de vídeos, atividades lúdicas como pinturas de desenhos dos macroinvertebrados, caçapalavras, palavras cruzadas e visualização na lupa estereoscópica dos organismos coletados. Portanto o presente estudo utilizando os macroinvertebrados aquáticos vem ser uma boa forma de trabalhar a educação ambiental e mostra uma ótima aceitação pelos alunos, com isso trabalhos deste tipo vêm dinamizar e ajudar a educação ambiental nas escolas.
\end{abstract}

Palavras-chave: Invertebrados. Meio Ambiente. Sensibilização.

\begin{abstract}
In the evaluation of aquatic environments, macroinvertebrates stand out for their sensitivity to the various anthropic impacts, so these organisms function as bioindicators of the quality of ecosystems. In this sense, a study was carried out in an urban stream in the municipality of Santarém-PA, where the macroinvertebrates were collected at three points in this stream, where the results showed environmental changes at the most urbanized point. These results were socialized for students at a Santarém Municipal School Teaching School with lectures, video presentations, play activities such as paintings of macroinvertebrates, wordplay, crossword puzzles and visualization in the stereoscopic magnifying glass of the collected organisms. Therefore, the present study using aquatic macroinvertebrates is a good way to work with environmental education and shows great acceptance by the students, as this kind of work has helped to promote environmental education in schools.
\end{abstract}

Key-words: Invertebrates. Environment. Awareness.

1 Universidade Federal do Oeste do Pará.

2 Universidade Federal do Pará.

3 Universidade Federal do Oeste do Pará, Instituto de Ciências e Tecnologia das Águas. 


\section{Resumen}

En la evaluación de los ambientes acuáticos, los macroinvertebrados se distinguen por su sensibilidad a diversos impactos antropogénicos, por lo que estos organismos funcionan como bioindicadores de la calidad del ecosistema. En este sentido, se realizó un estudio en un arroyo urbano en la ciudad de Santarém-PA, donde se recolectaron macroinvertebrados en tres puntos de este arroyo, donde los resultados mostraron cambios ambientales en el punto más urbanizado. Estos resultados se socializaron para los estudiantes en una escuela de la Red de Educación Municipal de Santarém con conferencias, presentaciones en video y actividades lúdicas como el dibujo de macroinvertebrados, la búsqueda de palabras, los crucigramas y la visualización estereoscópica de los organismos recolectados. Por lo tanto, este estudio que utiliza macroinvertebrados acuáticos es una buena manera de trabajar la educación ambiental y muestra una gran aceptación por parte de los estudiantes, con este trabajo para simplificar y ayudar a la educación ambiental en las escuelas.

Palabras clave: Invertebrados. Medio Ambiente. Conciencia.

\section{Introdução}

O meio ambiente saudável é fundamental para todos os seres vivos. Segundo a Constituição Federal brasileira "todos têm direito ao meio ambiente ecologicamente equilibrado, bem de uso comum do povo e essencial à sadia qualidade de vida, impondo-se ao Poder Público e à coletividade o dever de defendê-lo e preservá-lo para os presentes e futuras gerações" (BRASIL, 1988, p. 127).

Neste contexto, a educação ambiental é ferramenta essencial na resolução de problemas ambientais, pois visa o processo onde o indivíduo e a coletividade construam valores sociais, conhecimentos, atitudes e competências voltadas para conservação do meio ambiente, bem de uso comum e necessário à sadia qualidade de vida da sociedade (BRASIL, 1999).

A Educação Ambiental é considerada inicialmente como uma preocupação dos movimentos ecológicos com a prática de conscientização, que seja capaz de chamar a atenção para a má distribuição do acesso aos recursos naturais, assim como ao seu esgotamento, e envolver os cidadãos em ações sociais ambientalmente apropriadas (CARVALHO, 2006).

No entanto, a educação ambiental ganhou notoriedade com a promulgação da Política Nacional de Educação Ambiental e, por meio dela, foi estabelecida como obrigatoriedade no ensino formal da educação brasileira. A lei 9.765/99 precisa ser mencionada como um marco importante da história da educação no Brasil porque ela resultou de um longo processo de interlocução entre ambientalistas, educadores e governos (BRASIL, 1999).

Importante salientar que a educação ambiental não é somente uma prática pedagógica sobre ecologia, mas uma ferramenta que fornece conhecimento para a participação dos cidadãos nas discussões e decisões sobre questões ambientais (REIGOTA, 2010). De nada adianta falar sobre o meio ambiente, sem mudar os comportamentos individuais e sociais (REIGOTA, 2006).

Nas últimas décadas o meio ambiente, no que tange aos ecossistemas aquáticos, tem sido fortemente alterado em função de múltiplos impactos ambientais decorrentes de atividades antrópicas (MORENO; CALLISTO, 2005). Os diversos impactos antrópicos incluem assoreamento, introdução de espécies exóticas, eutrofização artificial, homogeneização da calha do rio, construção de barragens, 
aumento do desmatamento e extração de recursos naturais (GOULART; CALLISTO, 2003; HALL et al., 2006). Todas essas atividades antrópicas ocorrem na Amazônia (COUCEIRO et al., 2010).

Nos centros urbanos, em geral, os cursos d'água recebem aporte de esgotos domésticos e industriais in natura, além de sedimentos e lixo, resultando na modificação da sua estrutura física, química e biológica (SILVA, 2007; COUCEIRO et al., 2006, 2007). Assim a educação ambiental é um tema muito discutido atualmente devido a necessidade de uma melhoria do mundo em que vivemos (GUEDES, 2006).

Dentre as várias ferramentas de educação ambiental voltadas para a conservação de sistemas aquáticos, temos o uso de macroinvertebrados aquáticos. Macroinvertebrados são uma importante ferramenta para avaliação de perturbações ambientais (GOULART; CALLISTO 2003; BUSS, BAPTISTA; NESSIMIAN, 2003), devido ao seu tamanho, fácil amostragem, relativamente fácil identificação em grupos taxonômicos de família (e.g. ROSENBERG; RESH, 1993) e, principalmente, por responderem rapidamente com mudanças na composição, riqueza, abundância e estrutura trófica mediante ao impacto antrópico (COUCEIRO et al., 2011).

Sendo potenciais bioindicadores da qualidade das águas, os macroinvertebrados aquáticos podem ser utilizados através de práticas pedagógicas para a sensibilização ambiental das pessoas, especialmente, de crianças e de adolescentes em idade escolar. Algumas abordagens são incentivadas, como palestras, oficinas, teatro e elaboração de guias (manuais ou cartilhas) como de Sonoda (2009), Nascimento e Hamada (2012) e Paciencia et al. (2015), com uso de muitas figuras, as quais estão associadas às informações técnicas com linguagem voltada ao público leigo.

O uso desses organismos voltados para a educação ambiental embora ainda seja incipiente, apresenta um grande potencial voltado para a sensibilização ambiental, na cidade de Santarém - PA, onde é crescente a degradação sobre os sistemas aquáticos. Portanto, o objetivo deste trabalho foi de sensibilizar alunos de uma escola da Rede Municipal de Ensino de Santarém - PA quanto à importância da conservação dos igarapés da cidade, utilizando macroinvertebrados aquáticos coletados ao longo de um igarapé da parte urbana do município.

\section{Material e métodos}

Área de estudo: microbacia do Igarapé do Urumari

O Igarapé do Urumari situa-se na zona urbana, parte leste, do município de Santarém - PA. O igarapé possui uma extensão de aproximadamente $7,5 \mathrm{Km}$, com nascente na Serra do Saubal localizada no bairro da Vigia, percorrendo pelos bairros Santo André, Urumari, São José Operário, Jutaí, Uruará e Área Verde, com sua foz na denominada zona de confluência entre os rios Amazonas e Tapajós (PIMENTEL; MELO, 2014) (Figura 1). 
Figura 1 - Igarapé do Urumari, Santarém, Pará

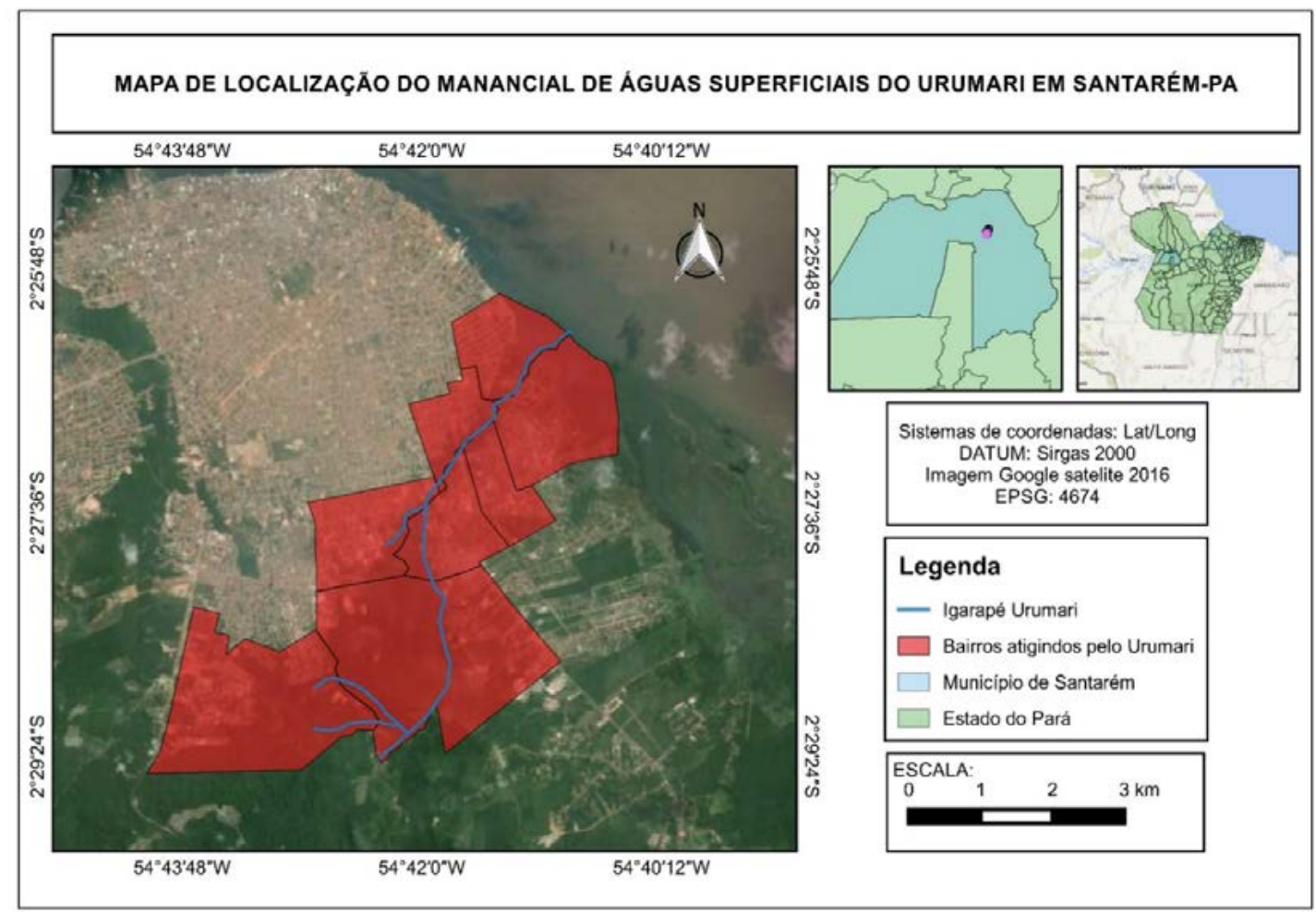

Fonte: Elison José Mota, 2016.

Sua nascente está dentro da Área de Proteção Ambiental (APA) Saubal (lei de criação a Lei Municipal número 18.715 de 29 de agosto 2011). Essa APA possui 1.538 metros quadrados e 156 hectares e abrange os bairros Nova República, Santo André, Bela Vista e Vigia. A sua criação tem por objetivos: promover o uso sustentado dos recursos naturais, proteger a biodiversidade, proteger os recursos hídricos e os remanescentes de floresta, proteger o patrimônio arqueológico e cultural, promover a melhoria da qualidade de vida da população, manter o caráter rural da região, evitar o avanço da ocupação urbana na área protegida (SANTARÉM, 2011).

Entretanto a partir da década de 1980, surgiram vários bairros no sentido Leste-Oeste da cidade de Santarém, de modo que alguns trechos do igarapé Urumari sofreram intensos impactos gerados pelo crescimento desordenado da população santarena, mas também pela instalação e atividades de madeireiras, serrarias, olarias, criação de pequenos e grandes animais na área, retiradas de areia, balneários, represas ao longo do seu curso e ainda serve de sumidouro dos efluentes urbanos (PROJETO URUMARI VIVO, 2011). Assim, apesar da criação da APA, o igarapé Urumari vem tendo alterações ambientais mesmo dentro da APA e, neste sentido um trabalho de educação ambiental voltado para temática do cuidado e proteção deste manancial é de grande valia.

\section{Coleta dos Macroinvertebrados e Avaliação da qualidade das águas}

As coletas foram realizadas em outubro de 2014 em três pontos: ponto 1: nascente, ponto 2: trecho médio e ponto 3: foz do igarapé Urumari. Em cada trecho foram realizadas quinze amostragens 
de macroinvertebrados aquáticos, coletados com rede entomológica em trechos de $50 \mathrm{~m}$. Ainda em campo foram medidos a temperatura da água, oxigênio dissolvido, com um oxímetro portátil (Oakton, modelo DO 110), e pH, condutividade elétrica com um potenciômetro/condutivímetro portátil (Oakton, model waterproof $\mathrm{pH} / \mathrm{con} 10 \mathrm{~m}$ ) e velocidade da correnteza pelo método flutuador.

Para avaliar a qualidade das águas do igarapé Urumari de modo simples, rápido e que permitisse o melhor entendimento de crianças em idade escolar, foi utilizado o índice BMWP (Biological Monitoring Work Party) modificado por Silva et al. (2011). O BMWP é um índice de pontuação de famílias de macroinvertebrados (em alguns casos classe ou ordem), que utiliza a presença ou ausência destes nas amostras, onde cada táxon corresponde a um valor para ser atribuído no índice. O método é bastante utilizado no Brasil para monitoramento ambiental com uso de macroinvertebrados, por ser rápido e fácil de usar, levando em consideração uma pontuação atribuída aos insetos de 0 a 10 onde os táxons com numeração próxima a dez significa alta tolerância à poluição e os que se aproximam de zero baixa tolerância à poluição, uma tabela com a indicação destes valores é usada nas medidas, o resultado final se dá pela soma destes valores e esse valor indica o grau de poluição de cada ponto do ambiente aquático pesquisado (Tabela 1).

Tabela 1 - Pontuação atribuída aos macroinvertebrados de acordo com o método BMWP

\begin{tabular}{|c|c|c|}
\hline Valor & Significado & Cor \\
\hline 101 a 120 & Águas muito limpas, sem poluição evidente & Azul \\
\hline 61 a 100 & Águas com algum sinal de poluição orgânica & Verde \\
\hline 36 a 60 & Águas poluídas com matéria orgânica & Amarelo \\
\hline 16 a 35 & Águas muito poluídas por matéria orgânica & Laranja \\
\hline$>15$ & Águas fortemente poluídas por matéria orgânica & Vermelho \\
\hline
\end{tabular}

Fonte: (SILVA et al., 2011).

\section{Trabalho na Escola}

A segunda etapa do estudo foi realizada em 27 de fevereiro de 2015 consistiu nas atividades com alunos de uma escola de ensino fundamental do município de Santarém com aula expositiva, apresentação de vídeos cedidos pelo Instituto Nacional de Pesquisas da Amazônia sobre os macroinvertebrados aquáticos, sobre a importância dos macroinvertebrados como bioindicadores da qualidade das águas, atividades lúdicas como pinturas de desenhos dos macroinvertebrados, caça-palavras, palavras cruzadas e visualização na lupa estereoscópica dos organismos coletados. Além de informações sobre o igarapé Urumari, demostrando a problemática de degradação que o igarapé vem sofrendo nas últimas décadas e propostas de ação para minimizar esses impactos, buscando despertar, nas crianças um cuidado com a natureza, no que tange a recuperação e proteção dos mananciais, visando sensibilizar as crianças para a importância que o igarapé tem na vida delas e para mostrar que os macroinvertebrados que vivem neste igarapé são fundamentais para manter o equilíbrio e a qualidade do ambiente. Essas atividades envolveram 60 crianças entre nove e 12 anos, do turno matutino da escola. 


\section{Resultados}

\section{Avaliação do Igarapé urumari}

A nascente deveria ser o ponto mais preservado para comparação com os resultados dos outros dois trechos amostrados no igarapé. Porém, o trecho médio localizado no bairro do Urumari se encontra melhor preservado que o trecho de nascente escolhido, devido ao difícil acesso a este, dentro de uma fazenda onde a entrada só é permitida pelos moradores do bairro. O terceiro ponto, localizado na foz do igarapé Urumari pode ser considerado o mais impactado pela ação do homem, devido a sua localização entre casas que ficam muito próximas a sua margem, que utilizam fossas sem nenhum tipo de saneamento básico adequado. A pesquisa registrou 22 famílias de invertebrados aquáticos, pertencentes a seis ordens, distribuídos nos três pontos pesquisados: Diptera, Ephemeroptera, Trichoptera, Odonata, Hemiptera e Plecoptera, pertencentes à classe Insecta, e duas outras classes, a Hirudinea e Crustacea.

Assim a caracterização do igarapé Urumari foi: No ponto 1, trecho de nascente, recebeu 95 pontos no índice BMWP (SILVA et al., 2011), indicando algum sinal de poluição. O ponto 2, trecho médio do igarapé, recebeu 108 pontos, sendo classificado como de águas limpas, sem poluição evidente. Já o ponto 3, trecho foz, recebeu somente 53 pontos, indicando águas impactadas com matéria orgânica, decorrente da acumulação dos despejos de esgoto ao longo do igarapé (Tabela 2). 
Tabela 2 - Famílias dos macroinvertebrados aquáticos coletados em trechos do igarapé Urumari, em Santarém-PA.

\begin{tabular}{|c|c|c|c|}
\hline CLASSE TAXONÔMICA & PONTO 1 & PONTO 2 & PONTO 3 \\
\hline \multicolumn{4}{|l|}{ DIPTERA } \\
\hline Ceratopogonidae & 4 & 4 & 4 \\
\hline Chironomidae & 2 & 2 & 2 \\
\hline Tipulidae & 5 & $* *$ & 5 \\
\hline Culicidae & 2 & $* *$ & $* *$ \\
\hline \multicolumn{4}{|l|}{ ODONATA } \\
\hline Libellulidae & 8 & 8 & $* *$ \\
\hline Aeshnidae & 8 & 8 & $* *$ \\
\hline Corduliidae & $* *$ & 8 & $* *$ \\
\hline Coenagrionidae & $* *$ & 6 & $* *$ \\
\hline \multicolumn{4}{|l|}{ TRICHOPTERA } \\
\hline Sericostomatidae & 10 & $* *$ & $* *$ \\
\hline Hydropsychidae & 5 & $* *$ & $* *$ \\
\hline Odontoceridae & 10 & 10 & $* *$ \\
\hline Calamoceratidae & 10 & 10 & $* *$ \\
\hline Philopotamidae & 8 & 8 & 8 \\
\hline \multicolumn{4}{|l|}{ HEMIPTERA } \\
\hline Veliidae & 3 & $* *$ & 3 \\
\hline Notonectidae & $* *$ & 3 & $* *$ \\
\hline \multicolumn{4}{|l|}{ COLEOPTERA } \\
\hline Elmidae & $* *$ & 6 & $* *$ \\
\hline \multicolumn{4}{|l|}{ EPHEMEROPTERA } \\
\hline Caenidae & 5 & 5 & 5 \\
\hline Leptophlebiidae & $* *$ & 10 & 10 \\
\hline Baetidae & 5 & 5 & 5 \\
\hline LEPIDOPTERA & 7 & 7 & $* *$ \\
\hline \multicolumn{4}{|l|}{ OUTROS } \\
\hline Hirudinea & 3 & $* *$ & 3 \\
\hline Crustacea & $* *$ & 8 & 8 \\
\hline TOTAL & 95 & 108 & 53 \\
\hline
\end{tabular}

Nota ${ }^{* *}=$ Táxons não encontrado no ponto amostrado

Fonte: Elaborado pelos autores.

\section{Sensibilização}

O projeto teve uma boa aceitação pela direção da escola, que não mediu esforços na organização do espaço. As crianças foram muito receptivas e demonstraram muito interesse pelo assunto abordado. Alguns ficaram interessados em como foi feita captura dos insetose, de como se dá a relação insetos e a poluição das águas. Outras demonstraram preocupação com o que foi mostrado, pois alguns relataram tomar banho no igarapé e confirmaram que trechos do igarapé Urumari já se encontram bem degradados pela ação do homem, principalmente, o despejo de resíduos sólidos. O resultado surtiu tanto efeito, devido a atenção que as crianças deram à apresentação que a comunidade escolar pediu para que o projeto se repetisse. 
As crianças ficaram muito empolgadas na realização das atividades lúdicas, principalmente com o caça-palavras e pintura. O momento mais aguardado pelas crianças foi a visualização dos macroinvertebrados, na lupa e nos frascos, onde puderam conhecer a morfologia de alguns insetos. Os alunos ficaram impressionados com a existência desse tipo de organismos nas águas dos igarapés, pois os mesmos pensavam que só existiam peixes nas águas (Figura 2).

Figura 2 - Atividades com os alunos da Escola

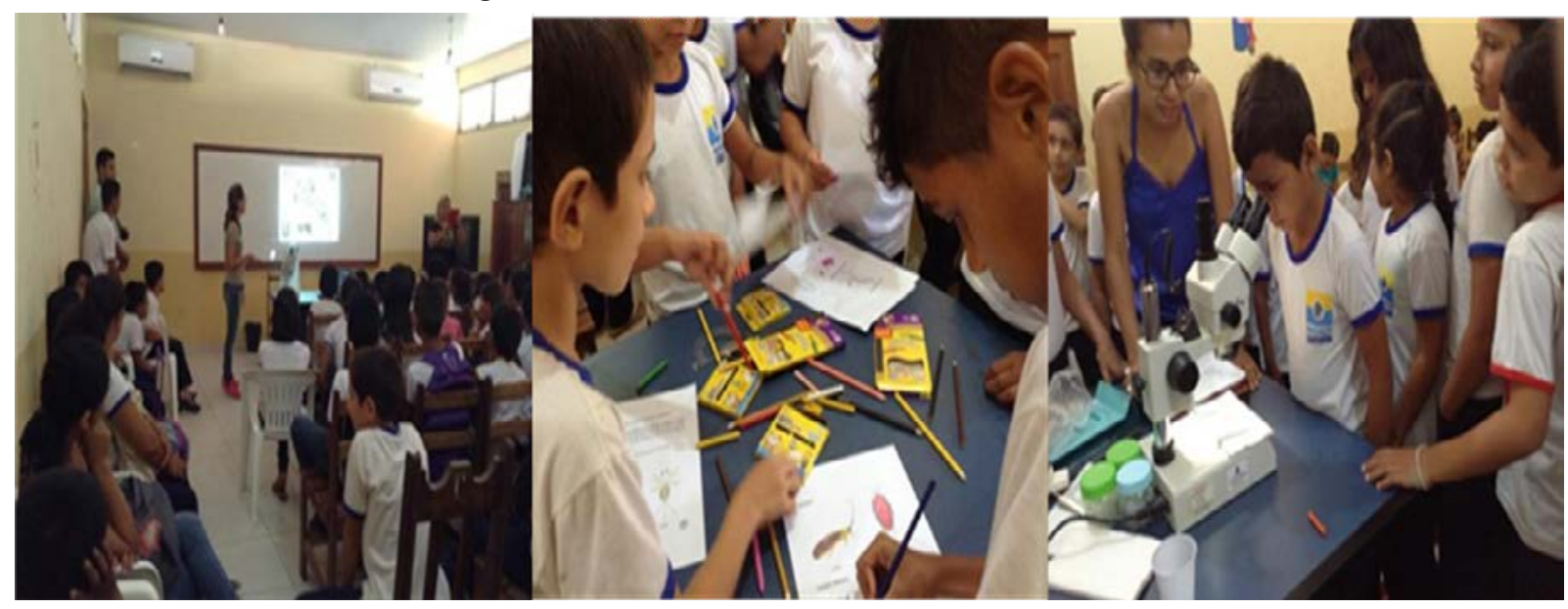

Fonte: Arquivo pessoal.

As crianças da escola perguntaram sobre os macroinvertebrados, as perguntas mais frequentes foram: "Existem mesmo esses tipos de bichos no igarapé?" "Além desses, tem outros bichos que vivem no igarapé?" Por que eles morrem quando tem poluição? E demonstraram interesse no cuidado não somente do igarapé Urumari, mas com o meio ambiente de uma forma geral, sempre muito atentas na socialização dos resultados e nos vídeos sobre a importância dos macroinvertebrados.

\section{Discussão}

A poluição é uma triste consequência da urbanização que resulta da retirada da vegetação marginal e/ou no despejo de esgoto não tratado nos igarapés, onde esses impactos antrópicos alteram drasticamente o ambiente (e.g. assoreamento) e a composição da comunidade de macroinvertebrados aquáticos, com perda na biodiversidade e substituição de espécies (COUCEIRO et al, 2006, 2007, 2012). Realidade constante dos igarapés urbanos na Amazônia (COUCEIRO et al., 2010).

Táxons de macroinvertebrados presentes na nascente e trecho médio do igarapé Urumari já não são mais encontrados no trecho foz (SALCEDO, 2006; MOREYRA; PADOVESI-FONSECA, 2015), tendo assim um maior nível de contaminação no igarapé na parte mais urbanizada (PIMENTEL et al., 2019), indicando também, que não há até o momento um plano de recuperação do igarapé diante das diversas formas de impactos ambientais (PIMENTEL; MELO, 2014), onde o poder público e os diversos segmentos da sociedade civil organizada, devem estar imbuídos de traçar um planejamento de ações mitigadoras, para a recuperação do Igarapé do Urumari, visando também recuperar outros mananciais que estão sendo impactados no município de Santarém (PIMENTEL et al., 2019). 
A prática de sensibilização ambiental de crianças com as atividades lúdicas utilizando os macroinvertebrados proporcionou de certa forma conhecimento interdisciplinar e acabou despertando o interesse dos alunos sobre a proteção do meio ambiente. Essa proposta de utilização dos bioindicadores como ferramenta para avaliar a qualidade de água chama a atenção dos alunos para a importância da conservação de rios e lagos (FRANÇA; CALLISTO, 2012). Atividades práticas realizadas com os alunos proporciona uma maior interação e participação por parte dos mesmos em conhecer mais sobre os insetos e como estes são usados na aplicação do biomonitoramento, trazendo a importância de se cuidar do meio ambiente de forma sustentável (SOUZA et al., 2017). Neste sentido a educação ambiental possibilita criar um processo pedagógico participativo e acaba despertando uma consciência crítica sobre a degradação ambiental, tendo o uso de cartilhas e as dinâmicas que envolvam questões ambientais como importantes metodologias, aproximando o problema ambiental da realidade vivenciada pelo estudante (PACIENCIA et al., 2015).

Dessa forma as crianças podem se tornar potenciais multiplicadores, possam em família ou com amigos divulgar a importância da conservação dos igarapés e a existência de uma fauna de macroinvertebrados pouco conhecida por eles, que somente sobrevive em boas condições ambientais, enquanto alguns grupos proliferam em águas impactadas e que essas águas perdem suas funções de lazer, abastecimento etc. A intenção é que havendo essa sensibilização em casa, seus pais se tornem mais atuantes, exigindo dos governos municipal e estadual ações de mitigação do impacto sobre este e outros igarapés.

A escola, portanto, possibilita traçar um norte em favor de um trabalho educativo que se preste a colaborar para o bem comum e busque a superação de um trabalho de caráter fragmentário, antropocêntrico, dissociado de uma concepção de ambiente considerado na amplitude de suas interrelações socioculturais (NOGUEIRA, 2016). É necessário promover uma reflexão sobre o efeito da ação humana no agravamento das perturbações ambientais, de sua responsabilidade como mentor de práticas e relações prudentes com o ambiente e do papel de cada cidadão na construção de um mundo melhor (PEREIRA et al., 2013).

Neste sentido, a escola é um local propício para abordar questões ecológicas, principalmente, aquelas que surgem do cotidiano, como, por exemplo, a degradação da mata ciliar. Assim, práticas educativas como estas, utilizando macroinvertebrados, atividades lúdicas, cartilhas ambientais, etc., vêm ganhando mais espaços e formas na educação, sendo uma importante ferramenta de sensibilização ambiental.

\section{Conclusão}

O uso de macroinvertebrados aquáticos vem ser uma boa forma de trabalhar a educação ambiental, visto que foi demonstrada uma ótima aceitação por crianças em idade escolar, sendo importante destacar que a educação ambiental é um processo de efeitos a curtos, médios e longos prazos. Trabalhos deste tipo dinamizam e ajudam a educação ambiental nas escolas e podem contribuir de forma significativa para um agir crítico e para uma prática de uma ecologia integral que respeite todo o meio ambiente. 


\section{Referências}

BRASIL. Constituição Federal. República Federativa do Brasil. Brasília: Senado, 1988. Disponível em: http: //www.planalto.gov.br. Acesso em: 03 de agosto de 2016.

BRASIL. Ministério do Meio Ambiente. Lei n. 9.795/1999. Dispõe sobre a educação ambiental, institui a Política Nacional de Educação Ambiental e dá outras providências. Disponível em: http:// www.mma.gov.br/port/conama/legiabre.cfm?codlegi=321. Acesso em: 22 de janeiro 2016.

BUSS, D. F.; BAPTISTA, D. F.; NESSIMIAN, J. L. Bases conceituais para a aplicação de biomonitoramento em programas de avaliação da qualidade da água de rios. Cad. Saúde Pública, Rio de Janeiro, v. 19, p. 465-473, 2003.

CARVALHO, I. C. M. Educação ambiental: a formação do sujeito ecológico. $2^{\mathrm{a}}$ ed. São Paulo: Cortez, 2006 256p.

COUCEIRO, S. R. M.; HAMADA, N.; FORSBERG, B.R.; FERREIRA, R.L.M. Effects of an oil spill and discharge of domestic sewage on the insect fauna of Cururu stream, Manaus, AM, Brazil. Brazilian Jounal of Biology, v. 66, p. 35- 44, 2006.

COUCEIRO, S. R. M.; HAMADA, N.; LUZ, S. L. B.; FORSBERG, B. R.; PIMENTEL, T. P. Deforestation and sewage effects on aquatic macroinvertebrates in urban streams in Manaus, Amazonas, Brazil. Hydrobiologia, v. 575, p. 271-284, 2007.

COUCEIRO, S. R. M.; HAMADA, N.; FORSBERG, B.R.; PADOVESI-FONSECA, C. Effects of anthropogenic silt on aquatic macroinvertebrates and abiotic variables in streams inthe Brazilian Amazon. Journal of Soils and Sediments, v. 10, p.89-103, 2010.

COUCEIRO, S. R. M.; HAMADA, N.; FORSBERG, B. R.; PADOVESI-FONSECA, C. Trophic structure of macroinvertebrates in Amazonian streams impacted by anthropogenic siltation. Austral Ecology, v. 36, p. 628-637, 2011.

COUCEIRO, S. R. M.; HAMADA, N.; FORSBERG, B. R.; PIMENTEL, T. P.; LUZ, S. L. B. A macroinvertebrate multimetric index to evaluate the biological condition of streams in the Central Amazon region of Brazil. Ecological Indicators, v.18, p. 118-125, 2012

FRANÇA, J. S.; CALLISTO, M. Macroinvertebrados bentônicos como bioindicadores de qualidade de água: experiências em educação ambiental e mobilização social. Revista Extensão, v. 2, p. 197-206, 2012.

GOULART, M. D.; CALLISTO, M. Bioindicadores de qualidade de água como ferramenta em estudos de impacto ambiental. Revista FAPAM, v. 2, p. 78- 85, 2003.

GUEDES, J. C. S. Educação ambiental nas escolas de ensino fundamental: estudo de caso. Garanhuns: Ed. Do autor. 2006.

HALL, JR. L. W.; KILLEN, W. D.; ANDERSON, S. D. "Charactezation of benthic communities and fhisical habitat in the Stanislaus, Tuolumne, and Merced Rivers, California". Environmental Monitoring and Assessment, v. 115, p. 223-264, 2006. 
MORENO, P.; CALLISTO, M. Bioindicadores da qualidade de água ao longo da Bacia do Rio das Velhas (MG). Universidade Federal de Minas Gerais. Instituto de Ciências Biológicas, 2005. 22 p.

MOREYRA, A. K.; PADOVESI-FONSECA, C. Environmental effects and urban impacts on aquatic macroinvertebrates in a stream of central Brazilian Cerrado. Sustain. Water Resour. Manag, v. 1, n. 2 , p. 125-136, 2015.

NASCIMENTO, J. M. C.; HAMADA, N. O mundo dos insetos aquáticos. Manaus, 2012. 32p.

NOGUEIRA, M. L. S. L. S. Práticas interdisciplinares em educação ambiental na educação básica: o que nos revelam as pesquisas acadêmicas brasileiras (1981-2012). 337f. Dissertação de Mestrado em Faculdade de Educação. Universidade Estadual de Campinas, SP, 2016.

PACIENCIA, G. P.; FURTADO. C. H.; SOUZA, F. S. T.; SOUTO, A. W. P.; GAVA, A. P. P. A utilização dos macroinvertebrados aquáticos de riachos do município de Vilhena - RO na confecção de cartilhas de Educação Ambiental. Revista Monografias Ambientais - REMOA, v.14, n.1, p.176 - 182, 2015.

PEREIRA, C. C.; SILVA, F. K.; RICKEN, I.; MARCOMIN, F. E. Percepção e Sensibilização Ambiental como instrumentos à Educação Ambiental. Revista Eletrônica Mestrado em Educação Ambiental, v. 30, n.2, p. $86-106,2013$.

PIMENTEL, D. R.; MELO, S. Proteção ambiental no igarapé do Urumari, cidade de Santarém, Pará, Brasil. Revista Em Foco, v. 11, n. 22, p. 7-13, 2014.

PIMENTEL, D. R.; MOTA, E. J.; ALVES, R. C. F.; RAMOS, P. C.; JESUS, A. K. S. (2019). Avaliação da qualidade da água do Igarapé do Urumari, Santarém, Pará. Revista Saúde e Meio Ambiente RESMA, Três Lagoas, v. 8, n.1, p. 153-161.

Projeto Urumari Vivo. Projeto socioambiental, 2011. 21p. Disponível em: http://www.fundodema.org.br.

REIGOTA, M. O que é educação ambiental. Brasiliense. Coleção primeiros Passos. São Paulo, 2006. 107p.

REIGOTA, M. Meio ambiente e representação social. $8^{a}$ ed. São Paulo: Cortez, v. 12, 2010. 96p.

ROSENBERG, D. M.; RESH V. H. Freshwater Biomonitoring and Benthic Macroinvertebrates. New York: Chapman \& Hall, 1993. 488p.

SALCEDO, A. K. M. Variação temporal e espacial e importância ecológica de macroinvertebrados aquáticos num córrego periurbano do Distrito Federal. Dissertação Mestrado. 86f. Universidade de Brasília, Brasília, 2006.

SANTARÉM. Lei no 18.715 de 29 de agosto 2011. Lei de Criação da Área de Proteção Ambiental (APA) Saubal. Santarém: Gabinete do prefeito.

SILVA, F. H.; FAVERO, S.; SABINO, J.; GARNÉS, S. J. A. Índices abióticos para avaliação da qualidade ambiental em trechos do tio Correntoso, Pantanal do Mato Grosso do Sul, Brasil. Maringá Editora. Acta Scientiarum. Biological Sciences, v. 33, p.289-299, 2011.

SILVA, N. T. C. Macroinvertebrados bentônicos em áreas com diferentes graus de preservação 
ambiental na Bacia do Ribeirão Mestre das Armas, DF. 99f. Dissertação de Mestrado em Ecologia. Universidade de Brasília, 2007.

SONODA, K. C. Humberto e Camila descobrem a ecologia dos rios. Brasília: Embrapa Informação Tecnológica, 2009. 60 p.

SOUSA, A. M.; SARMENTO, E. C.; SANTOS, L. S. G.; OLIVEIRA, L. S. O.; SANTOS, D. S. V. Educação ambiental e biomonitoramento aquático para redução de impactos ambientais no riacho Lamego: ações na escola Arlindo Fernandes de Oliveira, residencial Eugênio Coutinho. Revista Eletrônica Educação Ambiental em Ação. Caxias-MA, 2017.

\section{Diego Ramos Pimentel}

Possui graduação em Licenciatura Plena em Ciências Biológicas pela Universidade Federal do Pará (UFPA) - Campus de Santarém (2008). Especialização em Direito Ambiental pela Faculdade Internacional de Curitiba - Pólo de Santarém (2009). Mestrado em Ciências Ambientais pelo Programa de Pós-Graduação em Recursos Naturais da Amazônia pela Universidade Federal do Oeste do Pará (UFOPA) - Santarém (2011). Formação complementar no curso Amazônia: Meio Ambiente, Intervenção e Conservação, realizado no Oeste do Pará, pelo programa de Doutorado em Ciências do Meio Ambiente da Universidade do Quebec de Montreal (UQAM), Canadá (2014). Doutor em Ciências pelo Programa de Pós-Graduação Sociedade, Natureza e Desenvolvimento da UFOPA (2017). Membro do Laboratório de Taxonomia e Ecologia de Invertebrados Aquáticos (LETIA) do Campus Amazônia-UFOPA. Professor de Ciências na Rede Municipal de Ensino de Mojuí dos Campos/PA. Professor no Projeto Mundiar da Secretaria Estadual de Educação/PA. Trabalhou como Professor Substituto na UFOPA. Coordenador do Comitê em Defesa do Igarapé do Urumari. E-mail: diegorp82@yahoo.com.br

\section{Carla da Silva Paula}

Possui Graduação em Engenharia Sanitária e Ambiental pela Universidade Federal do Oeste do Pará (2017), atualmente vinculada ao curso de Mestrado do Programa de Pós-graduação em Estudos Antrópicos da Amazônia pela UFPA-Campus Castanhal. E-mail: carlapaula22@gmail.com ORCID: http://orcid.org/0000-0002-6328-5395

\section{Sheyla Regina Marques Couceiro}

Possui graduação em Ciências Biológicas pela Universidade Federal do Amazonas (2003), mestrado em Ciências Biológicas (Entomologia) pelo Instituto Nacional de Pesquisas da Amazônia (2005), doutorado em Ecologia pela Universidade de Brasília (2009) e especialização em Planejamento e Gerenciamento de Água (2010) pela Universidade Federal do Amazonas. Atualmente é Professora Adjunta na Universidade Federal do Oeste do Pará, lotada no Instituto de Ciências e Tecnologia das Águas. E-mail: sheylacouceiro@yahoo.com.br

ORCID: http://orcid.org/0000-0001-8186-4203 